\title{
Airborne Multiwavelength High Spectral Resolution Lidar (HSRL-2) observations during TCAP 2012: vertical profiles of optical and microphysical properties of a smoke/urban haze plume over the northeastern coast of the US
}

\author{
D. Müller ${ }^{1,2}$, C. A. Hostetler ${ }^{3}$, R. A. Ferrare ${ }^{3}$, S. P. Burton ${ }^{3}$, E. Chemyakin ${ }^{2}$, A. Kolgotin ${ }^{4}$, J. W. Hair ${ }^{3}$, A. L. Cook ${ }^{3}$,

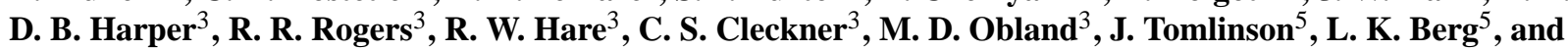 \\ B. Schmid ${ }^{5}$ \\ ${ }^{1}$ University of Hertfordshire, Hatfield, Hertfordshire, UK \\ ${ }^{2}$ Science Systems and Applications, Inc., NASA Langley Research Center, Hampton, VA, USA \\ ${ }^{3}$ NASA Langley Research Center, Hampton, VA, USA \\ ${ }^{4}$ Physics Instrumentation Center, Troitsk, Russia \\ ${ }^{5}$ Pacific Northwest National Laboratory, Richland, WA, USA
}

Correspondence to: D. Müller (d.mueller@herts.ac.uk)

Received: 14 January 2014 - Published in Atmos. Meas. Tech. Discuss.: 6 February 2014

Revised: 25 August 2014 - Accepted: 26 August 2014 - Published: 10 October 2014

\begin{abstract}
We present measurements acquired by the world's first airborne 3 backscatter $(\beta)+2$ extinction $(\alpha)$ High Spectral Resolution Lidar (HSRL-2). HSRL-2 measures particle backscatter coefficients at 355, 532, and $1064 \mathrm{~nm}$, and particle extinction coefficients at 355 and $532 \mathrm{~nm}$. The instrument has been developed by the NASA Langley Research Center. The instrument was operated during Phase 1 of the Department of Energy (DOE) Two-Column Aerosol Project (TCAP) in July 2012. We observed pollution outflow from the northeastern coast of the US out over the western Atlantic Ocean. Lidar ratios were $50-60 \mathrm{sr}$ at $355 \mathrm{~nm}$ and 60 $70 \mathrm{sr}$ at $532 \mathrm{~nm}$. Extinction-related Ångström exponents were on average $1.2-1.7$, indicating comparably small particles. Our novel automated, unsupervised data inversion algorithm retrieved particle effective radii of approximately $0.2 \mu \mathrm{m}$, which is in agreement with the large Ångström exponents. We find good agreement with particle size parameters obtained from coincident in situ measurements carried out with the DOE Gulfstream-1 aircraft.
\end{abstract}

\section{Introduction}

We developed an automated, unsupervised inversion algorithm. We tested the performance of the algorithm for the first time with data acquired with the world's first airborne 3 backscatter $(\beta)+2$ extinction $(\alpha)$ multiwavelength High Spectral Resolution Lidar (HSRL-2). The instrument acquired data during the first intensive observation period (730 July 2012) of the Department of Energy (DOE) TwoColumn Aerosol Project (TCAP) (Berg et al., 2014).

TCAP goals included quantifying aerosol properties and radiation and cloud characteristics at a location subject to both clear and cloudy conditions, and both clean and polluted conditions. HSRL-2 is the successor of HSRL-1, which has been operating in various field campaigns since 2006 (Hair et al., 2008). Like HSRL-1, HSRL-2 measures backscatter, extinction, and depolarization at $532 \mathrm{~nm}$ and backscatter and depolarization at $1064 \mathrm{~nm}$. In addition, HSRL-2 also measures extinction, backscattering, and depolarization at $355 \mathrm{~nm}$.

Raman lidar and high spectral resolution lidar provide high-quality backscatter and extinction coefficients. Multiwavelength lidar (MWL) allows, e.g., for aerosol typing (Burton et al., 2012). Aerosols of specific types show 
characteristic values of extinction-related and/or backscatterrelated Ångström exponents and extinction-to-backscatter (lidar) ratios and particle depolarization ratios. Aerosol typing information provides the climate modeling community with information on aerosol properties. Aerosol types can be related to their aerosol microphysical properties. Pure aerosol types possess a limited parameter range (particle size distribution, complex refractive index). Recently, attempts have been made to split mixtures of different aerosol types into pure types (Tesche et al., 2009; Burton et al., 2014; Noh, 2014), which can then be processed individually by inversion algorithms as described in the following.

The $3 \beta+2 \alpha$ lidar techniques are the basis for microphysical retrieval algorithms, e.g., inversion with regularization (Qing et al., 1989; Müller et al., 1999a; Veselovskii et al., 2002; Böckmann et al., 2005), singular-value decomposition, linear estimation, and principal component analysis techniques (Donovan and Carswell, 1997; Veselovskii et al., 2012; de Graaf et al., 2013), and the latest development, dubbed the "Arrange \& Average Algorithm" (Chemyakin et al., 2014). These algorithms allow for inverting the measured optical quantities into microphysical properties, such as particle size distribution or their integral properties and the complex refractive index. First successful applications of the method of inversion with regularization can be found in Müller et al. (1998), Veselovskii et al. (2002), and Böckmann et al. (2005).

In the case of inversion with regularization, the retrieved particle size distributions and the complex refractive index can be used to compute single-scattering albedo (scatteringto-extinction ratio), which is one of the most important parameters in climate forcing studies (Bond et al., 2013). Recently, simulation studies were carried out with the goal of investigating how accurately absorption and scattering coefficients can be inferred from the microphysical parameters. The results of these simulation studies will be presented in two contribution that are in preparation (Müller et al., 2014a, b).

With regard to multiwavelength Raman lidar the technology has matured to the point that ground based systems can be operated in a reliable manner at nighttime. EARLINET successfully operates a network of Raman lidars. Several of these systems are multiwavelength systems, which allow for detailed aerosol studies over Europe. Regardless of this capability, investigations of aerosol properties on the global scale cannot be done with ground-based systems. Comparably long signal-averaging times make these systems unsuitable for operation aboard fast-flying platforms, e.g., aircraft and satellites.

Thus, HSRL is the method of choice for airborne and space-borne applications in order to retrieve aerosol microphysical properties. Space missions of HSRL systems will be launched by NASA (http://www.nasa-usa.de/mission_pages/ station/research/experiments/1037.html) and ESA (Stoffelen et al., 2005; Ansmann et al., 2007; Flamant et al., 2008) in the next couple of years and. These lidar missions however do not provide the necessary number of measurement channels in order to carry out detailed investigations of particle microphysical properties. Multiwavelength HSRL is needed for providing high-quality microphysical data products. NASA Langley Research Center has developed two such systems, dubbed HSRL-1 (Hair et al., 2008) and HSRL-2.

HSRL-2 is the first airborne system capable of providing $3 \beta+2 \alpha$ data. This contribution aims at showing the results of microphysical particle properties that can be obtained from this instrument. The inversion method used for the retrievals is based on the concepts presented by Müller et al. (1999a) and Veselovskii et al. (2002). It has however been modified in order to allow for fast, unsupervised, automated data processing. Details on the inversion methodology will be presented in the aforementioned contributions that are in preparation.

These first results of HSRL-2 $3 \beta+2 \alpha$ measurements show pollution that was transported from the US and Canada out over the western Atlantic Ocean during TCAP. Our prototype software delivered profiles of particle microphysical parameters in near-real time from the inversion of the optical profiles measured by HSRL-2 aboard the NASA B-200 King Air aircraft. We show a comparison of our results to coincident in situ measurements of particle size parameters acquired by the DOE (Department of Energy) Gulfstream-1 (G-1) aircraft. Section 2 summarizes the methodologies. Section 3 presents measurement examples. Section 4 closes with a summary.

\section{Methodology}

The DOE G-1 aircraft was equipped to measure particle size distributions, chemical composition, and optical properties (Berg et al., 2014). The NASA King Air was equipped with HSRL-2 (http://abstractsearch.agu.org/meetings/2012/ $\mathrm{FM} /$ sections/A/sessions/A13K/abstracts/A13K-0336.html). HSRL-2 is the second-generation airborne HSRL developed at the NASA Langley Research Center. It is an airborne prototype for the lidar on the future Aerosol-Cloud-Ecosystem (ACE) mission recommended for implementation by NASA in the National Research Council's Decadal Survey for Earth Science (http://science.nasa.gov/earth-science/decadal-surveys/). It builds on the heritage of the HSRL-1 system (Hair et al., 2008) that has flown on more than 20 field campaigns since 2006.

\subsection{HSRL-2}

HSRL-2 operates at laser wavelengths of 355,532 , and $1064 \mathrm{~nm}$. HSRL-2 measures profiles of particle backscatter coefficients and linear particle depolarization ratios at 355,532 , and $1064 \mathrm{~nm}$, and particle volume extinction coefficients at 355 and $532 \mathrm{~nm}$. The extinction and backscatter coefficients at 355 and $532 \mathrm{~nm}$ are derived using the HSRL 
technique (Grund and Eloranta, 1991). An iodine-vapor filter is used for the extinction-coefficient measurements at $532 \mathrm{~nm}$. The backscatter coefficient at $1064 \mathrm{~nm}$ is measured using the standard backscatter technique (Fernald, 1984), but with the benefit of transfer of calibration using the $532 \mathrm{~nm}$ HSRL retrievals in clear-air regions of the profile (Hair et al., 2008). The measurements presented in this contribution did not indicate the presence of a significant amount of depolarizing aerosol particles. The channels used for the depolarization measurements will be described in a separate publication.

The uncertainties of the data are governed by various factors, like hardware and its calibration, signal calibration, signal-to-noise ratio, and signal averaging in time and space. A detailed description of calibration techniques and sources of error for the 532 and $1064 \mathrm{~nm}$ channels are given by Hair et al. (2008). The new feature of HSRL-2 compared to HSRL-1 is that it measures the particle volume extinction coefficient not only at $532 \mathrm{~nm}$, but also at $355 \mathrm{~nm}$, using an interferometric technique.

Data were sampled at $100 \mathrm{~m}$ horizontal and $15 \mathrm{~m}$ vertical resolutions and averaged to achieve the desired level of random uncertainty. For standard products, this is typically $1 \mathrm{~km}$ horizontally and $30 \mathrm{~m}$ vertically for backscatter and depolarization and $1 \mathrm{~km}$ horizontally and $150 \mathrm{~m}$ vertically for aerosol extinction. However, for the input to the microphysics retrieval for this study, data were averaged to 5 minutes and $150 \mathrm{~m}$ vertically to make the random error insignificant $(0.1-$ $3 \%$ ); studies are underway with regard to quantifying systematic errors. Thus we had had optimum conditions for this first test of the automated software as these errors are more than adequate for trustworthy microphysical retrievals (Müller et al., 1999b; Veselovskii et al., 2002; Böckmann et al., 2005).

\subsection{Automated, unsupervised inversion algorithm}

HSRL-2 is the motivation for developing the next generation of inversion methodology that allows us to process a high volume of data in an unsupervised, automated manner in real time with significantly enhanced accuracy of the inversion data products. Our ultimate goal is to develop software for application with a space-borne version of the multiwavelength HSRL.

The automated, unsupervised inversion software has been used for the analysis of the measurements. Details of the software package and results of simulations studies including uncertainty analysis will be presented in two contributions that are in preparation (Müller et al., 2014a, b). In the following we summarize the algorithm and some results of the simulation studies.

The mathematical equations that are used for solving the inverse ill-posed problem are the same used for the manual version of the inversion algorithm. The manual version has been applied in a multitude of studies by different lidar groups since 1997 (e.g., Müller et al., 1998, 2001; Murayama et al., 2004; Balis et al., 2010; Alados-Arboledas et al., 2011; Noh et al., 2011; Navas-Guzmán et al., 2013; Nicolae et al., 2013). The equations that connect the measured backscatter and extinction coefficients to the underlying microphysical particle properties, i.e., the particle size distribution and complex refractive index, are solved by the use of eight triangular-shaped basis functions that are logarithmicequidistantly distributed in an inversion window (Müller et al., 1999a, b). In this study we set the minimum particle radius of the inversion window to $30 \mathrm{~nm}$ and the maximum value to $8 \mu \mathrm{m}$. This size range was sufficient for the data analyzed in this study.

We use the data of $3 \beta+2 \alpha$ systems in the way described by Müller et al. (2001) and Veselovskii et al. (2002). We solve the equations by determining weight factors for the base functions (triangles), which then allow us to reconstruct approximations of the particle size distributions. The position of the triangles on the radius scale and their geometrical width is varied, such that we have several hundred different inversion windows within which the eight basis functions are distributed. An example that shows this distribution of triangle functions is shown in Fig. 1 in Müller et al. (1999a). We solve the equations for 91 inversion windows and for each inversion window the inversion is carried out for a grid of complex refractive indices. The real part varies between 1.325 and 1.8 . The step size is 0.025 . The imaginary part varies between 0 and 0.1 . The step size is 0.003 .

We apply parallelization in the computations, which increases data processing speed. For each $3 \beta+2 \alpha$ data set, we run the algorithm for the error-free data, and we carry out eight runs in which the data are distorted by a random noise of $15 \%$; see also Veselovskii et al. (2002) and Sawamura et al. (2014). Details on error analysis will be presented by Müller et al. (2014a).

In the manual version of the algorithm we used to average all individual solutions that fell within a prescribed value (threshold value) of the discrepancy, as described by Müller et al. (1999b) and Veselovskii et al. (2002). This discrepancy threshold was determined from simulation studies. We optimized the automated scheme, compared to the manual version, using simulation studies. We found that using the 500 solutions with the lowest discrepancies provide us with better inversions results. Details will be presented by Müller et al. (2014a).

All in all, 573300 individual solutions were generated for each data point on 17 July 2012 (see Fig. 4). The data processing time was $22 \mathrm{~s}$ for each optical data point, i.e., the error-free and eight error runs combined with each of the 91 inversion windows and the grid of 700 complex refractive indices. These results were used to produce the profiles of microphysical properties shown in Fig. 4. We obtain mean values and uncertainties that are defined in terms of 1 standard deviation. 
Simulation studies were carried out for the automated version to test the performance. A sensitivity analysis was done for two different error model in order to test the robustness of the automated software from the mathematical point of view and for testing if the knowledge of the error models that describes the measurement errors of the optical input data is significant. One error model is based on extreme error simulations in which each measurement channel is given the maximum value of an assumed measurement error, e.g., 5, 10, 15 , or $20 \%$. This kind of sensitivity analysis with respect to measurement errors had previously been done for the manual inversion algorithm. In the automated version, we used the same measurement error scenarios, but we introduced a Gauss error-distribution model in addition. This means that, for example, for a measurement error of $15 \%$ in a measurement channel, this $15 \%$ measurement error has a Gauss-like probability distribution. A weighting of the measurement error is thus introduced.

To give an impression on the simulation results, we summarize a few numbers. We tested 2880 optical data sets that are representative of 48 mono-modal particle size distributions: mean radii are between 20 and $300 \mathrm{~nm}$. Geometrical standard deviation (mode width) was 1.5, 1.7, 1.9, 2.1, 2.3, 2.5. Effective radii were between $30 \mathrm{~nm}$ and $2.44 \mu \mathrm{m}$. We tested real parts of 1.4, 1.5, 1.6, and 1.7 and we will include 1.3 in the next round of simulations. Imaginary parts were $0,0.0001,0.001,0.0025,0.005,0.0075,0.01,0.015,0.02$, $0.025,0.03,0.035,0.04,0.045$, and 0.05 . We tested measurement errors in which each channel of the $3 \beta+2 \alpha$ system has $5,10,15$, and $20 \%$ error. We tested the extreme error model (Müller et al., 1999b) and the model in which the errors have a Gauss-like probability distribution. We also tested four error scenarios in which measurement uncertainties differ between the different measurement channels.

The preliminary analysis shows the following results. Effective radius can on average be retrieved to $30 \%$ uncertainty. Uncertainty in the volume concentration can reach $50 \%$, but in most cases stays within $30 \%$. An exact quantification of the meaning of "most cases" will be given in our future contributions. Surface-area concentration can be retrieved to $30 \%$ or better. Number concentration shows an uncertainty of $70 \%$ or less in approximately $50 \%$ of the simulations. Most of the simulations stay within $100 \%$ uncertainty, but we find outliers. The real part can be retrieved to 0.05 in approximately $50-70 \%$ of the cases. The main challenge is the imaginary part. It is less than $50 \%$ in $50 \%$ of the simulations. The other $50 \%$ of simulated cases shows uncertainties that can reach several $100 \%$ uncertainty. We are currently analyzing these cases. We also look into difference of retrieval errors with regard to the use of the two error models applied to the optical input data.

We assume that we will not be able to retrieve the imaginary part to better than $0.005 i$. We believe than any better accuracy is unrealistic in view of the limited optical data set of $3 \beta+2 \alpha$ data, measurement errors, data averaging in time

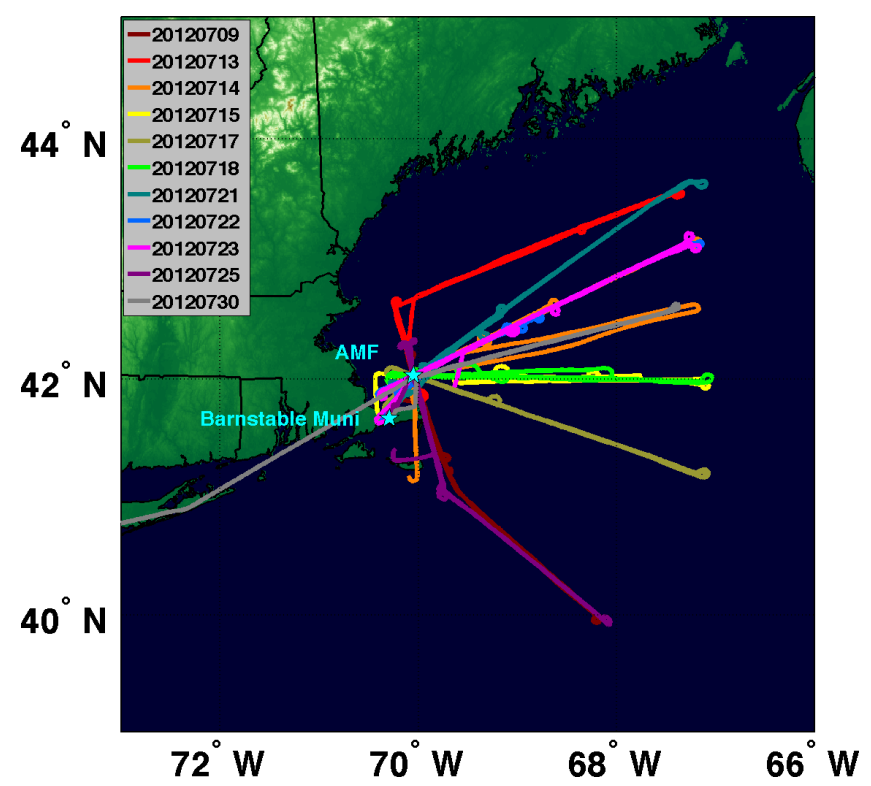

Figure 1. Flight tracks of B-200 King Air during TCAP 2012. Flight days are given in the legend. Each flight took approximately $3.5-4 \mathrm{~h}$.

and space, errors introduced by the inversion methodology, and constraints/assumptions used in the data inversion, as for example the fact that we cannot retrieve the exact shape of the particle size distribution. The main question is if there is a pattern in the uncertainties of the imaginary part, e.g., a pattern in which specific combinations of large/small Ångström exponents, high/low lidar ratios, and ratios of lidar ratios show these high errors in the imaginary part.

\section{Results and discussion}

The first phase of TCAP was characterized by outflow of pollution out over the western Atlantic Ocean. Smoke from fires that occurred in Canada may have episodically contributed to this outflow. A description of the air circulation pattern in the period from 9 to 25 July 2012 is given by Berg et al. (2014).

Figure 1 shows the flight tracks of the aircraft missions, see also Fig. 2 in Berg et al. (2014). HSRL-2 acquired data on 11 days between 7 and 30 July 2012, which includes the transit flights between NASA Langley Research Center, VA, and Barnstable Airport $\left(41.67^{\circ} \mathrm{N}, 70.29^{\circ} \mathrm{W}\right)$, MA. The B200 flew approximately $3-3.5 \mathrm{~h}$ during each of the research flights. In this contribution we focus on the measurements carried out on 17, 22 and 25 July 2012.

Optical depths measured with the AERONET Sun photometer at Barnstable Airport varied between 0.06 and 0.6 at $500 \mathrm{~nm}$ (level 2.0 data). Maximum daily-mean optical depth was 0.46 on 18 July and 0.33 on 17 July 2012. Another AERONET Sun photometer was operated at a coastal station at $41.3^{\circ} \mathrm{N}, 70.55^{\circ} \mathrm{W}$. Optical depth varied between 0.046 

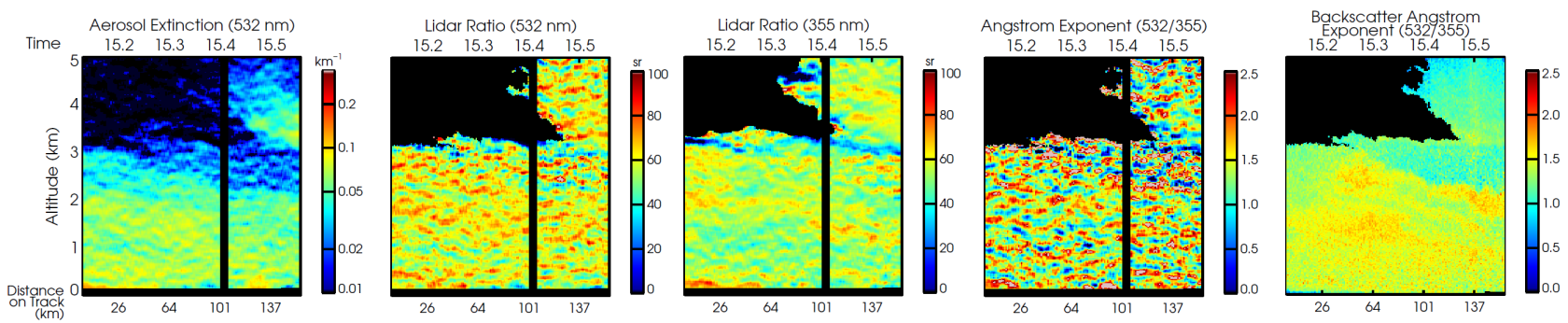

Figure 2. Curtain plot of the HSRL-2 measurement on 17 July 2012, 15:12-15:55 UTC. The time axis is in decimal hours. The distance flown during this time is shown on the bottom $x$ axis. Shown are the mean values of the profiles of (a) the extinction coefficient at 532, the lidar ratios at (b) 532 and (c) $355 \mathrm{~nm}$, (d) the extinction-related and (e) the backscatter-related Ångström exponent at $355 / 532 \mathrm{~nm}$. Each profile is based on a $10 \mathrm{~s}$ signal sampling rate. The vertical resolution is $150 \mathrm{~m}$.

and 0.5 (at $500 \mathrm{~nm}$ ). Daily-mean optical depth was 0.39 on 18 July and 0.24 on 17 July 2012 ; level 1.5 data.

The mean height of the pollution layers did not exceed $4 \mathrm{~km}$ a.s.l. with few exceptions in some portions of the flight tracks. The G-1 flew inside the pollution layers at various flight levels, and also carried out spirals from near sea level to the top of the pollution layers on several occasions. Details of the flight patterns are described by Berg et al. (2014). The B-200 flew at 8-9 km a.s.l., and thus always stayed above the pollution layers. For our comparison we selected only those flight segments during which the G-1 carried out spirals during or shortly after overflights by the B-200 aircraft. The maximum allowed distance from the HSRL profile to the approximate center of the spiral was $35 \mathrm{~km}$. The time difference to the beginning or end of the spiral of the G-1 was at most $22 \mathrm{~min}$. The spiral took about 11-12 min to complete, and covered about $8 \mathrm{~km}$ on 17 July. In this way we obtained the best possible data from the G-1 for our comparison study.

Figure 2 shows the example of the HSRL-2 measurement on 17 July 2012. Most of the aerosol particles were below $3 \mathrm{~km}$ a.s.l. A plume reaching heights up to $5 \mathrm{~km}$ was encountered during a short segment of the flight. Extinction coefficients remained comparably stable throughout the flight. Optical depth over the ocean generally varied between 0.3 and 0.45 at $355 \mathrm{~nm}$ and between 0.2 and 0.25 at $532 \mathrm{~nm}$ on 17 July 2012.

The extinction-related Ångström exponent was on average 1.2-1.7. The patch-like structure of the backscatter-related Ångström exponent shows an inhomogeneous structure with values varying between 1 and 2.5. The lidar ratios at 355 and $532 \mathrm{~nm}$ varied on average between 50 and $70 \mathrm{sr}$ in the pollution layers. The lidar ratio at $355 \mathrm{~nm}$ was similar or slightly lower to the one at $532 \mathrm{~nm}$. There was no significant decrease of the Ångström exponent and the lidar ratios near the ocean surface, indicating that marine particles did not significantly contribute to the total aerosol load in the marine boundary layer.

Figure 3 shows results of the aerosol typing according to the methodology described by (Burton et al., 2012). The plume consisted of urban haze and patches of smoke. Berg

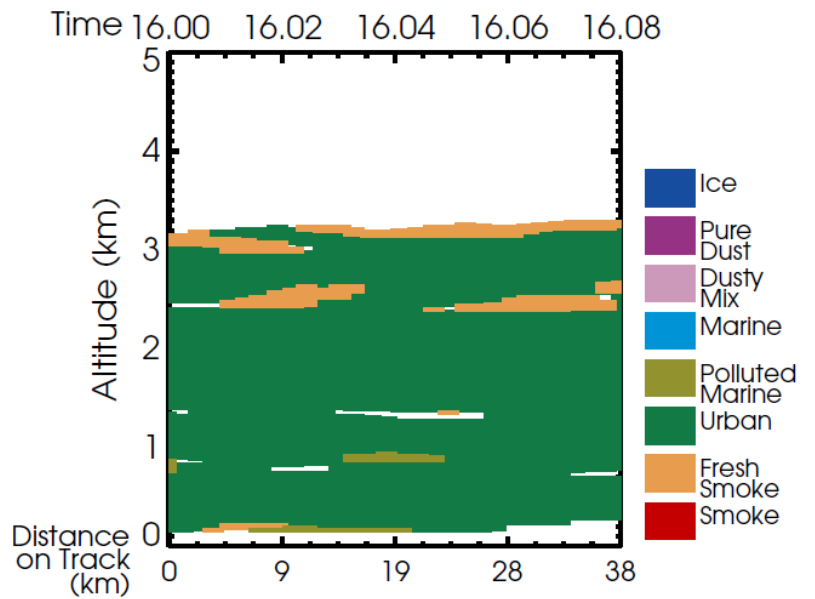

Figure 3. Curtain plot of aerosol typing of measurements from 16:00 to 16:05 UTC on 17 July 2012. Aerosol typing was carried out according to the scheme described by (Burton et al., 2012).

et al. (2014) carried out a detailed analysis of the air flow pattern on 17 July 2012 and determined the most likely origin of the air mass. For this work the authors used the Weather Research and Forecasting (WRF) model (Skamarock et al., 2008). Two nested domains were used. The outer domain contained most of North America and the inner domain contained the southeastern part of Canada and the northeastern part of the US. The WRF model results were used as input for back-trajectory computations with the FLEXPART model (Stohl et al., 1998; Brioude et al., 2013). The air-mass analysis shows that on 17 July 2012, the airflow was from western Canada across the Great Lakes to the Atlantic Ocean. Satellite images point to the presence of smoke particles. We assume that the smoke mixed with the urban haze over the northeastern US before it was transported out over the North Atlantic.

Berg et al. (2014) analyzed in detail the optical properties and the chemical composition of the pollution particles measured aboard the G-1 aircraft on 17 July 2014. The authors find that organics accounted for $73 \%$ of the mass fraction of 

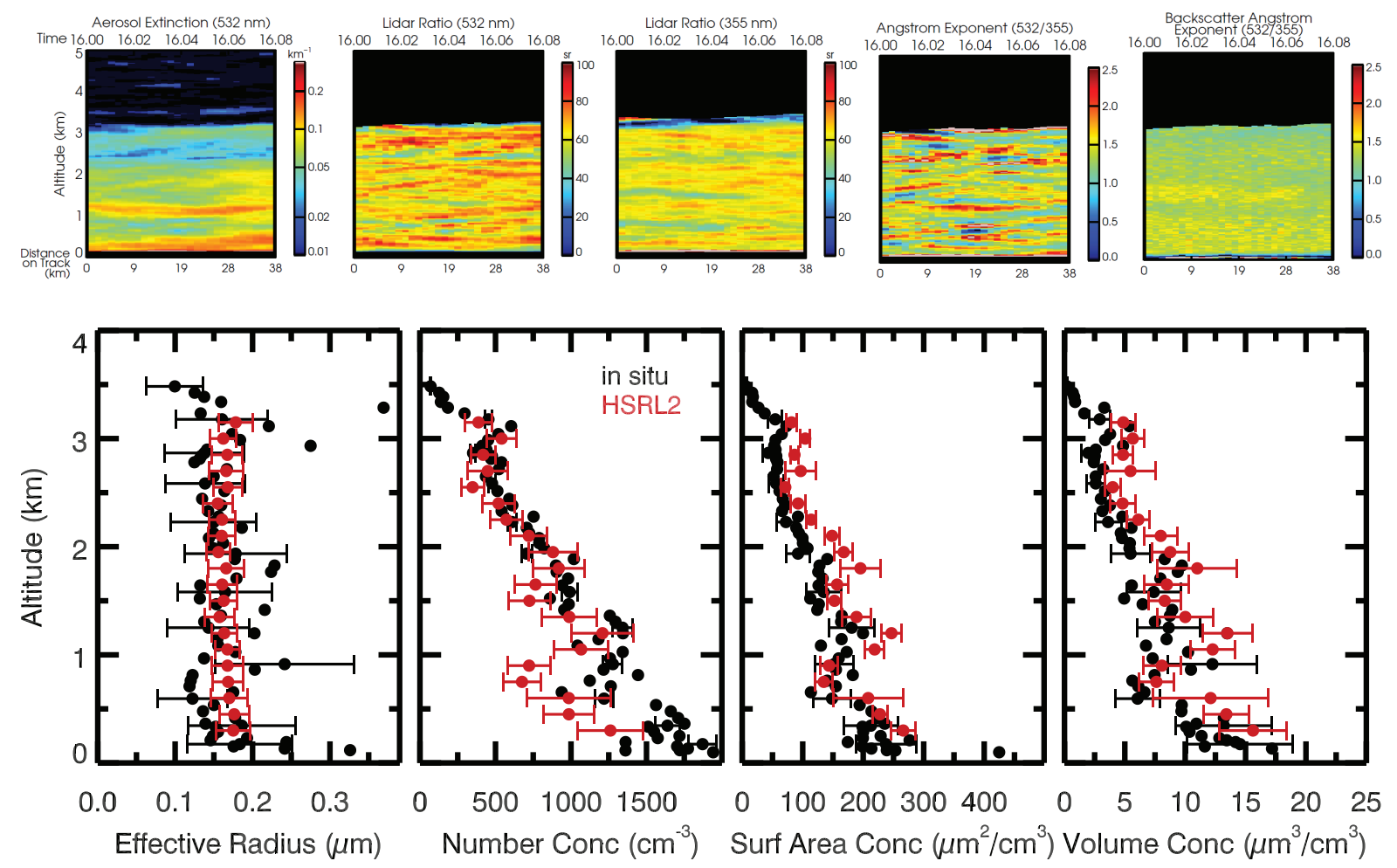

Figure 4. (Top) Curtain plots of an 5 min flight segment that was used for the data inversion. (Bottom) Microphysical parameters retrieved from the inversion method (red) and from the G-1 in situ measurements (black) on 17 July 2012. The measurement time was 16:0016:05 UTC for the inversion results and 15:45-15:56 UTC for the in situ data. The lidar measurements were obtained $2 \mathrm{~km}$ from the approximate G-1 spiral center. The inversion results represent height intervals of $150 \mathrm{~m}$. The in situ data were taken with considerably higher spatial resolution. Error bars of the individual in situ data points are composed of two types, counting and sizing. The error bars denote 1 standard deviation.

non-refractory particles. Sulfates accounted for $19 \%$. Ammonium and nitrates contributed 6 and $3 \%$ to the mass fraction, see also Fig. 12 of Berg et al. (2014). The amount of fresh and agedsoot particles, and biomass burning aerosol particles was measured using the miniSPLAT single particle mass spectrometer (Zelenyuk et al., 2010). The authors found an increased level of biomass burning particles and conclude that the biomass burning smoke originated from long-range transport from Canada. Seven-day back-trajectory analysis and fire-spot detection showed that the particles most likely originated from wildfires in western Canada; see Fig. 13 in Berg et al. (2014).

We selected the measurement from 16:00 to 16:05 UTC for the inversion of the optical data into microphysical particle parameters. Note: the times given in the text and in the plots are in decimal hours.

Figure 4 shows the curtain plots for this 5 min flight segment. We averaged the individual optical profiles in this 5 min time segment, and we split the profiles into height layers of $150 \mathrm{~m}$ geometrical depth. We obtained 20 sets of $3 \beta+2 \alpha$ coefficients, which then were processed with our automated algorithm. The data processing including error analysis for these 20 data points took approximately $6 \mathrm{~min}$.
We generated nearly 11.5 million individual solutions from which 2000 solutions were accepted according to the mathematical and physical constraints used in our algorithm. We then produced the profiles of the microphysical particle parameters from these 2000 solutions.

Figure 4 shows that effective radius does not significantly vary with height. It is approximately $0.2 \mu \mathrm{m}$, which is characteristic of urban aerosols and/or smoke, e.g., Müller et al. (2007), and references therein. The inversion results agree within error bars with the in situ measurements. The sampling volume of the in situ probe is significantly smaller than the sampling volume of the lidar. Small-scale variations in particle effective radius cannot be resolved with our inversion methodology. Number, surface-area and volume concentration obtained from data inversion and in situ measurements are close to each other.

The analysis was carried out very carefully, considered cut-off effects of aircraft inlets, calibration curves from aircraft instruments, collection efficiency factors of the in situ instruments, errors that might arrive from the inversion, as well as humidity growth factors that need to be considered in the in situ measurements. 
In general, the size range within which in situ instruments collect particles is different from the size range used in the data inversion. If the lower radius is changed in the inversion scheme, for example from a lower to a higher value, effective radius increases and number concentration decreases. An example of how changing the lower radius limit can alter particle size parameters is given in Table 1 of Wandinger et al. (2002). This effect of variable lower and upper limits must be considered in any kind of study that compares data from remote sensing instruments, which use data inversion methods, to data from in situ probes. In our study, we compare approximately the same lower radius range; i.e., inversion results use as a lower limit approximately $54 \mathrm{~nm}$, and the in situ measurements start measuring at approximately $50 \mathrm{~nm}$ radius. With regard to the upper threshold, we used a radius of approximately $6 \mu$ mfor the inversion, and a radius of $5.35 \mu \mathrm{m}$ for the in situ data.

Figure 5 shows the correlation of the Angström exponent measured with HSRL-2 versus the effective radius determined with the inversion algorithm and with the in situ instruments, respectively. Figure 6 shows the correlation of the effective radius, number, surface area, and volume concentration obtained from the lidar-data inversion and the in situ measurements. We averaged the in situ data across $150 \mathrm{~m}$ height intervals for this comparison; 17-56 data points were averaged in each of the height bins. The plots also show the results for the measurements on 22 and 25 July 2012; on these two days spiral flights of the G-1 were carried out. The number of data points that can be used for the comparison is significantly smaller on these two days.

The correlation shown in Fig. 5 is comparably high for effective radius obtained with our inversion algorithm. Figure 6 shows a larger scatter of the correlation of effective radius between the effective radius from the inversion method and from the in situ measurements. This result has to be expected despite the high quality of the data we used from both methods. We compare data products from two different methods, i.e., Ångström exponents and effective radius from HSRL-2 and particle size from in situ measurements. Several reasons can be the cause of the weaker correlation; e.g., (1) there is no perfect collocation in the measurement space and time of the two instruments, (2) in situ instruments dry the particles before a humidity correction is applied, even though a humidity correction did not seem necessary in the present case, (3) the in situ measurements were taken with considerably higher vertical resolution (spirals) than the Angström exponents measured with HSRL-2, and subsequently averaged to the vertical resolution that was used in the data inversion of the HSRL-2 measurements, and (4) the atmospheric volume observed by the lidar is considerably larger than the measurement volume of the in situ instruments, and thus averaging effects of the observed air volume may play a role, too. The weaker correlation between the effective radius measured with the in situ instruments and the Ångström

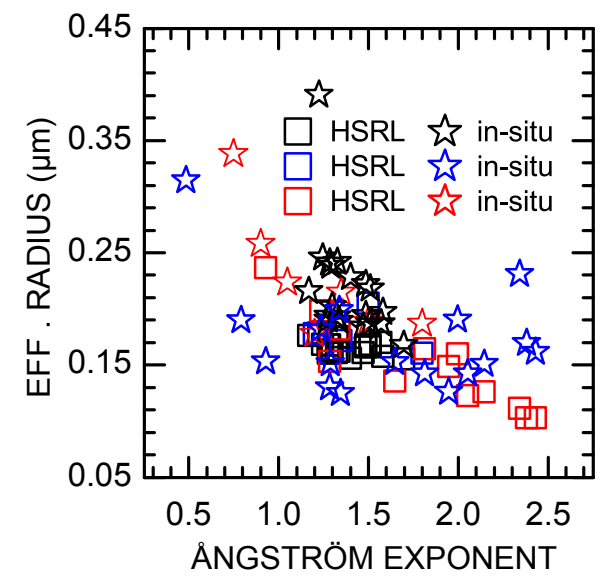

Figure 5. Correlation of Ångström exponents measured with HSRL-2 versus the effective radius (in $\mu \mathrm{m}$ ) obtained from data inversion (boxes) and versus the effective radius measured in situ (open stars): 17 July (black), 22 July (red), and 25 July (blue).

exponents measured with HSRL-2 (Fig. 5) may also explain the weaker correlation of the data products shown in Fig. 6.

Mean values of the effective radius from data inversion are on average lower than the effective radius from the in situ measurements; see Fig. 6. The same holds true for number concentration. We find the opposite behavior for surface area and volume concentration. In view of the fact that this is the first test of our automated software with experimental data, and in view of the various error sources involved in both methods, we consider this comparison satisfactory. A more detailed comparison study will include data from three more field campaigns that took place in 2013 and 2014.

We computed uncertainty bars for the data points available from both methods ( $150 \mathrm{~m}$ height intervals). Uncertainties in number concentration are $34 \% \pm 15 \%$ and $30 \% \pm 13 \%$ from in situ and from data inversion, respectively. Uncertainties in surface-area concentration are $39 \% \pm 17 \%$ and $14 \% \pm 7 \%$ from in situ and data inversion. Uncertainties in volume concentration are $52 \% \pm 20 \%$ and $21 \% \pm 7 \%$. Effective radius shows uncertainties of $38 \% \pm 15 \%$ and $12 \% \pm 2 \%$. The error bars for effective radius from the inversion are propagated from surface and volume error bars assuming no correlation, which may lead to overestimates of the uncertainty. This is a very simplified presentation of the uncertainties from both methods. We have only a few data points available, the errors distribution is not Gauss distributed, and there are some outliers.

\section{Conclusions}

We presented the first results of aerosol measurements with NASA Langley Research Center's High Spectral Resolution Lidar, HSRL-2. We used HSRL-2 data to test the 

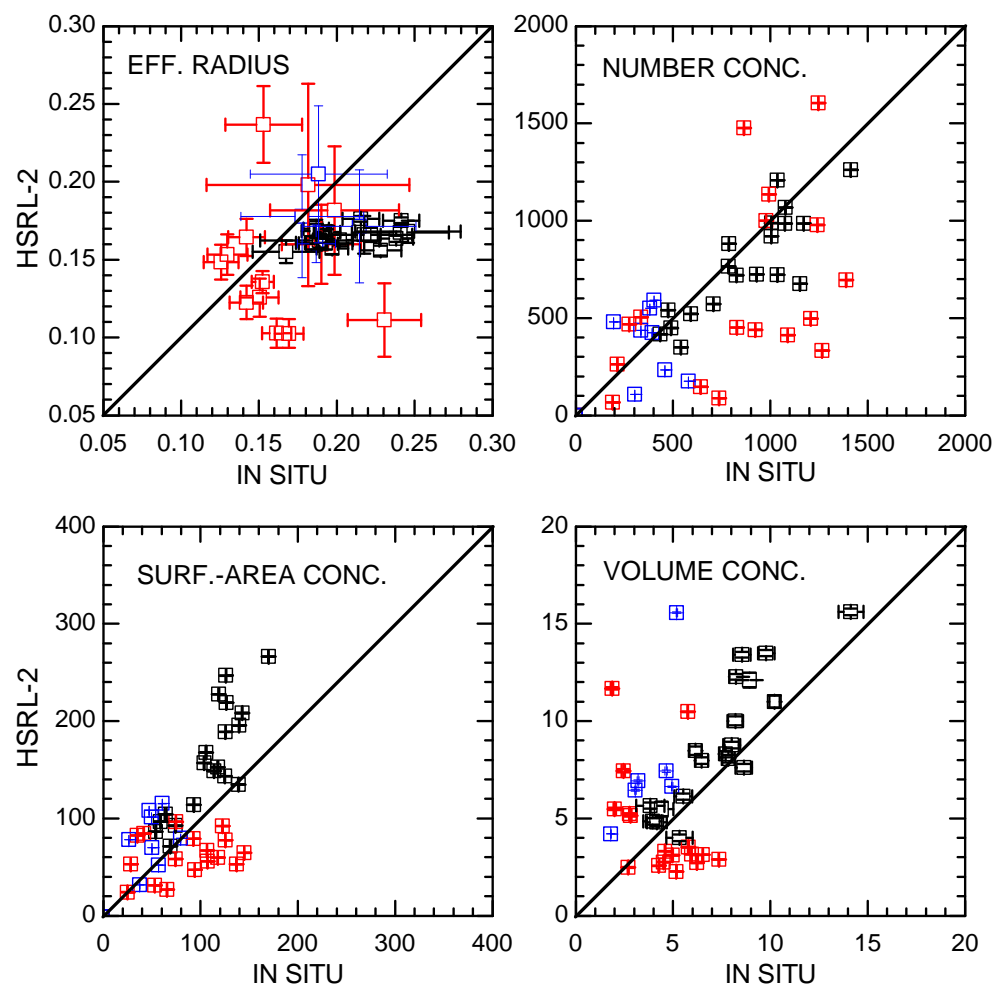

Figure 6. Correlation between inversion results and in situ results for effective radius, number concentration (1/cm), surface-area concentration $\left(\mu \mathrm{m}^{2} \mathrm{~cm}^{-3}\right)$, and volume concentration $\left(\mu \mathrm{m}^{3} \mathrm{~cm}^{-3}\right.$ ) on 17 July (black), 22 July (red), and 25 July (blue). Error bars denote 1 standard deviation and describe the variation of the data points in the $150 \mathrm{~m}$ thick layers that were used in the data inversion. Each data point has its own uncertainties, and it follows from the measurement uncertainties (in situ) and data inversion errors. The average uncertainty of each of the four data products is mentioned in the text. Effective radius uncertainties are propagated from volume and surface-area uncertainties without taking potential correlation into account, and therefore may be overestimated. The three data points of the in situ measurements shown in Fig. 5 (effective radius above $0.31 \mu \mathrm{m}$ ) are not shown in this figure.

performance of our newly developed automated, unsupervised inversion algorithm with experimental data for the first time. HSRL-2 and the inversion software are being used to investigate the possibility of operating a 3 backscatter +2 extinction HSRL in space. Such an instrument could be part of NASA's ACE (Aerosol-Cloud-Ecosystems) mission.

We analyzed the measurements from 17, 22, and 25 July 2012 that were made during the first intensive observation period (7-30 July 2012) of the Department of Energy (DOE) Two-Column Aerosol Project (TCAP). TCAP took place over the Atlantic Ocean off the coast of Cape Cod, MA. Particle effective radius and Ångström exponents indicate that urban haze and/or biomass-burning smoke was observed (Müller et al., 2007; Alados-Arboledas et al., 2011; Nicolae et al., 2013). Chemical analysis carried out aboard the G-1 aircraft and simulations with the WRF model and back-trajectory analysis also point to the presence of urban haze and smoke particles (Berg et al., 2014). We find a satisfactory correlation of our data products with in situ measurements of particle size distributions measured aboard the DOE G-1 aircraft.
The lidar microphysical retrievals are not as detailed as those made in situ aboard the G-1 aircraft. However, the curtains of horizontally and vertically resolved microphysical information enable characterization of the aerosol properties above and below the G-1 flight altitude, and hence characterization of the entire column. In particular, the lidar curtains of these aerosol properties will be important for TCAP radiative closure studies. The data from HSRL-2 can be used for studies of aerosol direct and indirect effects, investigations of aerosol-cloud interactions, assessment of chemical transport models, and air quality studies.

We continue to investigate the quality of our inversion data products. Additional data are available from the DISCOVER-AQ campaigns that took place in California in January-February 2013, in Texas in September 2013, and in Colorado in July-August 2014. We will further improve the quality of other data products like the imaginary part of the complex refractive index that allows us to compute profiles of the absorption coefficient and the single-scattering albedo. We will study the accuracy of retrieving these optical parameters as wavelength-dependent quantities. 
Acknowledgements. The authors thank the NASA Langley B-200 King Air flight crew or their outstanding work and support during the research flights. Support for the HSRL-2 flight operations during TCAP was provided by the DOE ARM program: Interagency Agreement DE-SC0006730. Support for data analysis was provided in part by the DOE Atmospheric System Research (ASR) program. Support for the development of HSRL-2 was provided by the NASA Science Mission Directorate, ESTO, AITT, and Radiation Science Program. We thank C. Flynn, R. Wagener, L. Gregory, and P. Russell at the Barnstable AERONET station for providing data. The AERONET data at MVCO are provided by $\mathrm{H}$. Feng and H. M. Sosik.

\section{Edited by: V. Amiridis}

\section{References}

Alados-Arboledas, L., Müller, D., Navas-Guzmán, J. L. G.-R., Pérez-Ramírez, D., and Olmo, F. J.: Optical and microphysical properties of fresh biomass burning aerosol retrieved by Raman lidar, and star- and sun-photometry, Geophys. Res. Lett., 38, L01807, doi:10.1029/2010GL043004, 2011.

Ansmann, A., Wandinger, U., Rille, O. L., Lajas, D., and Straume, A. G.: Particle backscatter and extinction profiling with the spaceborne high-spectral-resolution Doppler lidar ALADIN: methodology and simulations, Appl. Opt., 46, 6606-6622, 2007.

Balis, D., Giannakaki, E., Müller, D., Amiridis, V., Kelektsoglou, K., Rapsomanikis, S., and Bais, A.: Estimation of the microphysical aerosol properties over Thessaloniki, Greece, during the SCOUT-O3 campaign with the synergy of Raman lidar and sunphotometer data, J. Geophys. Res., 115, D08202, doi:10.1029/2009JD013088, 2010.

Berg, L. K., Fast, J. D., Barnard, J. C., Burton, S. P., Cairns, B., Chand, D., Comstock, J. M., Dunagan, S., Ferrare, R. A., Flynn, C. J., Hair, J. W., Hostetler, C. A., Hubbe, J., Johnson, R., Kassianov, E. I., Kluzek, C. D., Kollias, P., Lamer, K., Lantz, K., Mei, F., Miller, M. A., Michalsky, J., Ortega, I., Pekour, M., Rogers, R. R., Russell, P. B., Redemann, J., III, A. J. S., SegalRosenheimer, M., Schmid, B., Shilling, J. E., Shinozuka, Y., Springston, S. R., Tomlinson, J. M., Tyrrell, M., Wilson, J. M., Volkamer, R., Zelenyuk, A., and Berkowitz, C. M.: The TwoColumn Aerosol Project: phase I overview and impact of elevated aerosol layers on aerosol optical depth, J. Geophys. Res., submitted, 2014.

Böckmann, C., Miranova, I., Müller, D., Scheidenbach, L., and Nessler, R.: Microphysical aerosol parameters from multiwavelength lidar, J. Opt. Soc. America-A, 22, 518-528, 2005.

Bond, T. C., Doherty, S. J., Fahey, D. W., Forster, P. M., Berntsen, T., DeAngelo, B. J., Flanner, M. G., Ghan, S., Karcher, B., Koch, D., Kinne, S., Kondo, Y., Quinn, P. K., Sarofim, M. C., Schultz, M. G., Schulz, M., Venkataraman, C., Zhang, H., Zhang, S., Bellouin, N., Guttikunda, S. K., Hopke, P. K., Jacobson, M. Z., Kaiser, J. W., Klimont, Z., Lohmann, U., Schwarz, J. P., Shindell, D., Storelvmo, T., Warren, S. G., and Zender, C. S.: Bounding the role of black carbon in the climate system: A scientific assessment, J. Geophys. Res., 118, 5380-5552, 2013.

Brioude, J., Arnold, D., Stohl, A., Cassiani, M., Morton, D., Seibert, P., Angevine, W., Evan, S., Dingwell, A., Fast, J. D., Easter, R. C., Pisso, I., Burkhart, J., and Wotawa, G.: The La- grangian particle dispersion model FLEXPART-WRF version 3.1, Geosci. Model Dev., 6, 1889-1904, doi:10.5194/gmd-61889-2013, 2013.

Burton, S. P., Ferrare, R. A., Hostetler, C. A., Hair, J. W., Rogers, R. R., Obland, M. D., Butler, C. F., Cook, A. L., Harper, D. B., and Froyd, K. D.: Aerosol classification using airborne High Spectral Resolution Lidar measurements - methodology and examples, Atmos. Meas. Tech., 5, 73-98, doi:10.5194/amt-5-73-2012, 2012.

Burton, S. P., Vaughan, M. A., Ferrare, R. A., and Hostetler, C. A.: Separating mixtures of aerosol types in airborne High Spectral Resolution Lidar data, Atmos. Meas. Tech., 7, 419-436, doi:10.5194/amt-7-419-2014, 2014.

Chemyakin, E., Müller, D., Burton, S., Kolgotin, A., Hostetler, C., and Ferrare, R.: Arrange \& Average algorithm for the retrieval of aerosols parameters from multiwavelength HSRL/Raman lidar data, Appl. Opt., in press, 2014.

de Graaf, M., Apituley, A., and Donovan, D.: Feasibility study of integral property retrieval for tropospheric aerosol from Raman lidar data using principle component analysis, Appl. Opt., 52, 2173-2186, 2013.

Donovan, D. P. and Carswell, A. I.: Principal component analysis applied to multiwavelength lidar aerosol backscatter and extinction measurements, Appl. Opt., 36, 9406-9424, 1997.

Fernald, F. G.: Analysis of atmospheric lidar observations: Some comments, Appl. Opt., 23, 652-653, 1984.

Flamant, P., Cuesta, J., Denneulin, M.-L., Dabas, A., and Huber, D.: ADM-Aeolus retrieval algorithms for aerosol and cloud products, 60, 273-268, 2008.

Grund, C. J. and Eloranta, E. W.: The University of Wisconsin High Spectral Resolution Lidar, Opt. Eng., 30, 6-12, 1991.

Hair, J. W., Hostetler, C. A., Cook, A. L., Harper, D. B., Ferrare, R. A., Mack, T. L., Welch, W., Izquierdo, L. R., and Hovis, F. E.: Airborne high-spectral-resolution lidar for profiling aerosol optical profiles, Appl. Opt., 47, 6734-6752, 2008.

Müller, D., Wandinger, U., Althausen, D., Mattis, I., and Ansmann, A.: Retrieval of physical particle properties from lidar observations of extinction and backscatter at multiple wavelengths, Appl. Opt., 37, 2260-2263, 1998.

Müller, D., Wandinger, U., and Ansmann, A.: Microphysical particle parameters from extinction and backscatter lidar data by inversion with regularization: Theory, Appl. Opt., 38, 2346-2357, 1999a.

Müller, D., Wandinger, U., and Ansmann, A.: Microphysical particle parameters from extinction and backscatter lidar data by inversion with regularization: Simulation, Appl. Opt., 38, 23582368, 1999 b.

Müller, D., Wandinger, U., Althausen, D., and Fiebig, M.: Comprehensive particle characterization from three-wavelength Ramanlidar observations, Appl. Opt., 40, 4863-4869, 2001.

Müller, D., Mattis, I., Ansmann, A., Wandinger, U., Ritter, C., and Kaiser, D.: Multiwavelength Raman lidar observations of particle growth during long-range transport of forest-fire smoke in the free troposphere, Geophys. Res. Letts., 34, L05803, doi:10.1029/2006GL027936, 2007.

Müller, D., Chemyakin, E., and Kolgotin, A.: Automated and Unsupervised Inversion of Multiwavelength Lidar Data, Part 1: Microphysical Parameters and Uncertainties Derived from Simulation Studies, in preparation, 2014a. 
Müller, D., Chemyakin, E., and Kolgotin, A.: Automated and Unsupervised Inversion of Multiwavelength Lidar Data, Part 2: Optical Parameters and Derived From Microphysical Data Uncertainties Inversion Products, in preparation, 2014b.

Murayama, T., Müller, D., Wada, K., Shimizu, A., Sekigushi, M., and Tsukamato, T.: Characterization of Asian dust and Siberian smoke with multi-wavelength Raman lidar over Tokyo, Japan in spring 2003, Geophys. Res. Letts., 31, L23103, doi:10.1029/2004GL021105, 2004.

Navas-Guzmán, F., Müller, D., Bravo-Aranda, J. A., GuerreroRascado, J. L., Granados-Muñoz, M. J., Pérez-Ramírez, D., Olmo, F. J., and Alados-Arboledas, L.: Eruption of the Eyjafjallajökull Volcano in spring 2010: Multiwavelength Raman lidar measurements of sulphate particles in the lower troposphere, J. Geophys. Res., 118, 1804-1813, doi:10.1002/jgrd.50116, 2013.

Nicolae, D., Nemuc, A., Müller, D., Talianu, C., Vasilescu, J., Belegante, L., and Kolgotin, A.: Characterization of fresh and aged biomass burning events using multiwavelength Raman lidar and mass spectrometry, J. Geophys. Res., 118, 1-10, 2013.

Noh, Y. M.: Single-scattering albedo profiling of mixed Asian dust plumes with multiwavelength Raman lidar, Atmos. Environ., 95, 305-317, 2014.

Noh, Y. M., Müller, D., Mattis, I., Lee, H., and Kim, Y. J.: Vertically resolved light-absorption characteristics and the influence of relative humidity on particle properties: Multiwavelength Raman lidar observations of East Asian aerosol types over Korea, J. Geophys. Res., 116, D06206, doi:10.1029/2010JD014873, 2011.

Qing, P., Nakane, H., Sasano, Y., and Kitamura, S.: Numerical simulation of the retrieval of aerosol size distribution from multiwavelength laser radar measurements, Appl. Opt., 28, 52595265, 1989.

Sawamura, P., Müller, D., Hoff, R. M., Hostetler, C. A., Ferrare, R. A., Hair, J. W., Rogers, R. R., Anderson, B. E., Ziemba, L. D., Beyersdorf, A. J., Thornhill, K. L., Winstead, E. L., and Holben, B. N.: Aerosol optical and microphysical retrievals from a hybrid multiwavelength lidar dataset - DISCOVER-AQ 2011, Atmos. Meas. Tech. Discuss., 7, 3113-3157, doi:10.5194/amtd-7-31132014, 2014.
Skamarock, W. C., Klemp, J. B., Dudhia, J., Gill, D. O., Barker, D. M., Duda, M. G., Huang, X.-Y., Wang, W., and Powers, J. G.: A Description of the Advanced Research WRF Version 3, Rep. NCAR/TN-475+STR, Tech. rep., Boulder, CO, USA, 2008.

Stoffelen, A., Pailleux, J., Källn, E., Vaughan, J. M., Isaksen, L., Flamant, P., Wergen, W., Andersson, E., Schyberg, H., Culoma, A., Meynart, R., Endemann, M., and Ingmann, P.: The Atmospheric Dynamics Mission for global wind field measurement, Bull. Am. Meteorol. Soc., 86, 73-87, 2005.

Stohl, A., Hittenberger, M., and Wotawa, G.: Validation of the Lagrangian particle dispersion model FLEXPART against large scale tracer experiment data, Atmos. Environ., 32, 4245-4264, 1998.

Tesche, M., Ansmann, A., Müller, D., Althausen, D., Engelmann, R., Freudenthaler, V., and Groß, S.: Vertically resolved separation of dust and smoke over Cape Verde by using multiwavelength Raman and polarization lidar during SAMUM 2008, J. Geophys. Res., 114, D13202, doi:10.1029/2009JD011862, 2009.

Veselovskii, I., Kolgotin, A., Griaznov, V., Müller, D., Wandinger, U., and Whiteman, D. N.: Inversion with regularization for the retrieval of tropospheric aerosol parameters from multiwavelength lidar sounding, Appl. Opt., 41, 3685-3699, 2002.

Veselovskii, I., Dubovik, O., Kolgotin, A., Korenskiy, M., Whiteman, D. N., Allakhverdiev, K., and Huseyinoglu, F.: Linear estimation of particle bulk parameters from multi-wavelength lidar measurements, Atmos. Meas. Tech. Discuss., 4, 7499-7528, doi:10.5194/amtd-4-7499-2011, 2011.

Wandinger, U., Müller, D., Böckmann, C., Althausen, D., Matthias, V., Bösenberg, J., Weiss, V., Fiebig, M., Wendisch, M., Stohl, A., and Ansmann, A.: Optical and microphysical characterization of biomass-burning and industrial-pollution aerosols from multiwavelength lidar and aircraft measurements, J. Geophys. Res., 107, 8125, doi:10.1029/2000JD000202, 2002.

Zelenyuk, A., Imre, D., Earle, M., Easter, R., Korolev, A., Leaitch, R., Liu, P., Macdonald, A. M., Ovchinnikov, M., and Strapp, W.: In situ characterization of cloud condensation nuclei, interstitial, and background particles using the single particle mass spectrometer, SPLAT II, 82, 7943-7951, 2010. 